\title{
La vida de las palabras. Un diálogo posible entre Paulo Freire y Martin Heidegger
}

\author{
The life of words. A possible dialogue between paulo freire and \\ martin heidegger
}

José Beltrán Llavador ${ }^{1}$

Universidad de València

Jose.Beltran@uv.es

ORCID ID: https:/ / orcid.org/0000-0003-1065-3032

\section{Resumen}

Este artículo sugiere un hipotético diálogo entre Paulo Freire y Martin Heidegger. Ambos pensadores y educadores recuperan y recrean tradiciones filosóficas y educativas propias, abriendo una rica conversación con las voces del pasado, del presente y también del futuro. Cada uno de ellos ha inspirado una literatura abundante y creciente. Lo que no es frecuente, sino más bien excepcional, es encontrar referencias sobre los dos pensadores al mismo tiempo. Este texto pretende compensar esa ausencia. Al mismo tiempo, rinde homenaje al pedagogo brasileño, destacando la vigencia de su obra y la necesidad de reinventarla, así como anticipando su reconocimiento como patrimonio intangible de la humanidad.

Palabras clave: diálogo, educación, inédito viable, palabras, utopía.

$1 \quad$ El texto que se presenta es una versión revisada y actualizada de la conferencia invitada que se impartió en el IV Seminário Internacional de Educação, Teorias e Políticas: Paulo Freire e a Educação Superior, 5 a 7 de noviembre de 2013 en la Universidade Nove de Julho [UNINOVE], São Paulo [Brasil). Más información sobre el seminario en: https://pedagogiadavirtualidade.wordpress.com/2013/10/08/rede-instalacao-pedagogica-ecirculo-de-cultura-virtual-paulo-freire-na-educacao-superior/. El contenido de la conferencia fue un encargo realizado expresamente por la organización.

La actualización de este trabajo forma parte del proyecto de investigación "Las representaciones sociales de los contenidos escolares en el desarrollo de las competencias docentes" [PGC2018-094491-B-C32), financiado por el Ministerio de Ciencia, Innovación y Universidades y cofinanciado con fondos FEDER de la UE. 


\title{
Abstract
}

This article suggests a hypothetical dialogue between Paulo Freire and Martin Heidegger. Both thinkers and educators recover and recreate their own philosophical and educational traditions, opening a rich conversation with the voices of the past, the present and also the future. Each of them has inspired an abundant and growing literature. What is not frequent, but rather exceptional, is finding references to both thinkers at the same time. This text aims to compensate for this absence. At the same time, it pays tribute to the Brazilian pedagogue, highlighting the validity of his work and the need to reinvent it, as well as anticipating its recognition as an intangible heritage of humanity.

Key words: dialogue, education, unknown viable, words, utopia

\author{
O educador Paulo Freire \\ Foi, mirando uma utopia \\ Humanista e coherente \\ Com a sua ideologia, \\ Quem melhor interpretou \\ Toda esse sabedoria. \\ Medeiros Braga, Cordel a Paulo Freire
}

La filosofía de Heidegger tiene la pretensión y el estilo de una proclamación.

El gran arte de decir que no tiene nada que decir.

Karl Jaspers, Notas sobre Heidegger

\section{Acerca del diálogo}

El diálogo² entre Paulo Freire y Martin Heidegger plantea un contrafáctico empírico: qué hubiera sucedido si Freire y Habermas se hubieran encontrado y hubieran conversado. No hay respuesta a esta cuestión. Esta situación no se ha producido de facto, por tanto es imposible. Y sin embargo, siendo imposible, no es impensable. Desde el momento en que es pensable, ya es de algún modo posible, si quiera sea en el terreno de la conjetura, de la imaginación y de la creación. Así pues, nos vamos a mover en el espacio de un oxímoron, de una contra-dicción, en una suerte de nolugar, desplazándonos desde lo imposible hasta lo pensable, desde lo no-dicho hasta lo que se ha dicho en forma de escritura.

2 En un texto anterior sobre otro diálogo posible, entre Freirey Habermas, en esa ocasión, introducía el siguiente comentario: "El diálogo encuentra su más noble origen en la tradición socrática, que a su vez guarda precedentes importantes en el origen de la filosofía cuando, mediante caminos, estrategias o recorridos argumentativos [dia], dos interlocutores esgrimían razones [logos] con la finalidad de [con]vencer al otro. Lógicamente [en un sentido lógico y dialógico] el vencido no pierde realmente, sino que gana conocimiento. Es esa relación de confrontación racional, de discusión viva, de esgrima o pugilato argumentativo, de disenso, lo que da origen a la dialéctica, en sus expresiones más plurales a lo largo de la historia del pensamiento, como método de aproximación a la realidad." [Beltrán, 2003, p. 12]. 
Cada uno de los autores a los que se invita a dialogar forma parte y ha dado lugar a una constelación propia. Ambos, a su vez, recuperan y recrean las tradiciones filosóficas y educativas, dialogando al mismo tiempo con las voces del pasado, del presente y también del futuro. Cada uno de los dos ha inspirado una literatura abundante y creciente. Lo que no es frecuente, sino más bien excepcional, es encontrar referencias sobre los dos pensadores pensadores al mismo tiempo. ¿Cómo proceder entonces? Intentaré arrojar un poco de luz sobre Freire y Heidegger privilegiando, de entre su vasta producción, dos textos, como si fueran dos cuadros. "Picasso dijo en cierta ocasión que la luz de un cuadro procedía de otro cuadro. Así también la luz de cada escrito procede de otros escritos" [Axelos, 1980, p.7). Voy, pues, a examinar dos textos como si fueran dos cuadros, cuadros que a su vez nos abren a "modos de ver", a maneras de concebir y representar la realidad social, porque "la vista llega antes que la palabra." (Berger, 2000, p.13]. Voy a considerar, entonces, los pasajes como si fueran también paisajes. Primum videre, deinde philosophari.

\section{Pasajes y paisajes}

Los textos a los que prestaré atención no están elegidos al azar, sino que también pertenecen a una rica filiación de lo que podríamos denominar, en sentido muy amplio, "credos educativos". Dentro de este hilo conductor, nos encontramos con que algunos de estos credos adoptan el género epistolar: son cartas dirigidas no a un individuo en particular, sino a un sujeto social, a un lector potencial. En la estela de esta cadena de credos podría nombrarse, entre otras, las Cartas sobre la educación estética del hombre, de Schiller; el opúsculo de Kant ¿Qué es la ilustracion?; Mi credo pedagógico, de John Dewey; Carta a una maestra, de los alumnos de la escuela de Barbiana; el "Apéndice sobre artesanía intelectual", de Wright Mills; La carta de Albert Camus a su maestro y la carta de éste al recién nombrado premio nobel añadidas al final de El primer hombre; la conferencia La educación es educarse, de Hans-Georg Gadamer, a punto de cumplir los cien años de edad; y un largo etcétera. Todas ellas constituyen síntesis acerca de las convicciones educativas de sus respectivos autores.

En este caso las cartas elegidas resumen un credo pedagógico y un credo filosófico. Se trata de Cartas sobre el humanismo [a partir de ahora, CSH], de M. Heidegger (1947) y Cartas a quien pretende enseñar (a partir de ahora, CQPE], de P. Freire [1993]. Entre ambas obras han transcurrido 45 años, las dos son obras de madurez, tamizadas por una dilatada experiencia. Pero antes de asomarnos a este diálogo, es necesario recordar que este diálogo es asimétrico, en el siguiente sentido: Freire leyó a Heidegger en el marco del movimiento existencialista. Pero es improbable que Heidegger leyera a Freire. Sin embargo, podemos intentar leer, en parte, a Heidegger a través de Freire, y a Freire a través Heidegger.

Para Carlos Alberto Torres, Heidegger representa, siguiendo el título de uno de sus artículos, una de "las corrientes filosóficas que secundan la filosofía de Paulo Freire" [Torres, 1980). Torres señala cuatro influencias principales en el educador brasileño: el pensamiento existencial, la fenomenología, el pensamiento marxista y la filosofía hegeliana. Heidegger sería un caso singular dentro del primero. El existencialismo del filósofo alemán, que marca distancia con el de Sartre en la CSH, se articula en torno a la idea del existente humano (del Dasein). "El Dasein posee como estructura fundamental la temporalidad. La descripción fenomenológica que un Heidegger realiza en búsqueda de una analítica existencial del Dasein, plantea que éste se manifiesta como un ser cuyo carácter fundamental es estar-en-el-mundo, con su correspondiente comportamiento existencial, consistente en la facultad de desapropiación [aptitud que tiene el existente humano 
para absorberse en las cosas].” [Torres, 1980, p. 9]. En este sentido, Husserl había enfatizado la importancia de estar in media res, en el "meollo de las cosas". Mientras que Heidegger había resbalado, desde "cierta tonalidad afectiva", hacia la idea de la nada [in media nihih, "como si la única virtualidad del existente fuera la nada" [Torres, 1980, p. 9]. Esta precisión es importante porque ya deja ver una "tonalidad" o una actitud distinta, entre Freire y Heidegger: de extroversión o apertura en el primero - pues ser-en-el-mundo es también ser-con-los-otros-, y de introversión u oclusión en el segundo.

\section{Lenguaje y mundo}

Sin duda, uno de los temas más recurrentes y más importantes en la obra de Freire es el del lenguaje. Para Freire el lenguaje es aquello que hace posible una lectura de la realidad. En la conversación registrada en 1984 con otros dos interlocutores, observa lo siguiente: "Para mi es necesario leer el mundo, pero por encima de todo, escribir o reescribir el mundo quiere decir transformarlo." [Freire, Gadotti, Guimarães, 2001, p. 109]. No es casual que Freire comenzara enseñando sintaxis de la lengua portuguesa y que en sus escritos aparezcan continuos usos de las palabras como si formaran parte de una caja de herramientas con las que servirnos para armar y desarmar el mundo.

En la CSH, Heidegger, por su parte, observa que "el hombre no es sólo un ser vivo que junto a otras facultades posea también la del lenguaje. Por el contrario, el lenguaje es la casa del ser: al habitarla, el hombre ex-siste, desde el momento en que, guardando la verdad del ser, pertenece a ella." [CSH, 43]. Hay una diferencia de grado y de intensidad en la concepción y en el uso del lenguaje entre Freire y Heidegger. Si Freire ha sido considerado "peregrino de lo obvio" [Keenedy, 2004, p. 31 ], Heidegger podría ser considerado "embajador de lo inefable".

La cuestión del lenguaje, que es un hecho universal en los seres humanos, no es trivial. Para Heidegger "el lenguaje es la casa del ser. En su morada habita el hombre" [CSH, 11]. Para Freire, el lenguaje es el inter-locutor del mundo: la lectura de la palabra es la lectura del mundo, como sugiere Freire en su primera carta [CQPE, 28-42]. El lenguaje no duplica la realidad, no es un "espejo de la naturaleza", en expresión de Rorty [1983], sino que re-presenta, re-crea la realidad y re-inventa la realidad. Valga la apelación a la estrategia del como si nietzscheano, o lo que es lo mismo, a la necesidad de que los seres humanos se sirvan de "ficciones útiles" para aproximarse a la realidad, pero eso además supone la admisión de que el lenguaje también es convención, es invención. Dicho de otra manera, en términos Wittgenstein, "el lenguaje acompaña al mundo". Si se prefiere, el lenguaje forma parte de este mundo, es pensamiento y acción en el mundo, y por tanto, es contingente y deviene con el mundo; expresa y recrea el mundo, algo que por lo demás nos recuerda Freire en su metodología de la palabra generadora y en sus propuestas para tender puentes entre el texto y el contexto, entre las palabras [words] y el mundo [world]. Ahora bien, que el lenguaje sea un hecho universal no quiere decir que pueda darse, y que de hecho se dé, en las mismas condiciones, con las mismas pretensiones de validez, y con idénticos presupuestos. No podemos ignorar que todo discurso se despliega en contextos materiales y encierra dicción, pero también contra-dicción, que es acción y reacción, reflexión actuante y acción reflexiva, es posición y oposición, identidad y alteridad.

\section{Un giro educativo}

Siguiendo la tesis de Raymond Morrow y a Carlos Alberto Torres [2003, pp. 59-66], Freire formaría parte y sería uno de los principales promotores de un cambio de paradigma, de un 
giro educativo, que tuvo su punto de partida en Kant. "Además del giro epistemológico iniciado por Kant, los autores se detienen en el conocido 'giro lingüístico' iniciado el siglo pasado y que rechaza cualquier fundamentación fuerte del conocimiento fuera del lenguaje. En esta línea cabría mencionar la hermenéutica de Gadamer, el interaccionismo de George Herbert Mead, la teoría de los juegos del lenguaje del segundo Wittgenstein, y la teoría de la acción comunicativa de Habermas. Y a este último giro, los autores sugieren añadir un tercero, al que denominan 'giro educativo' (learning turn], que estaría protagonizado por Habermas y Freire, y que se justificaría porque ambos plantean el proceso de aprendizaje como el centro de su proyecto crítico, algo que podría implicar una revolución en la teoría social." (Beltrán, 2003, p. 17). Este giro educativo se concreta en la tarea por hacer en adelante de crítica al neoliberalismo, que Paulo Freire, poco antes de morir, transmitió a Carlos Alberto Torres en conversación telefónica, como él mismo cuenta en el "Prefacio" a su obra Educación y neoliberalismo. Ensayos de oposición [Torres, 2006], y cuyo prólogo escribí atendiendo a su invitación [Beltrán, 2006].

En cualquier caso, el rechazo por parte de Freire de esa asunción esencialista que mantiene que la realidad puede ser directamente conocida "en sí misma", haciendo abstracción del lenguaje, justifica, para los autores, su adscripción como pensador postfundacional o postmetafísico. No es trivial esa adscripción, porque en la tarea de conocer y de intervenir sobre la realidad social que nos explica y a la que damos explicación, el lenguaje juega un papel muy importante. De hecho, el lenguaje es un trabajo. Existir, observa Freire, es nombrar el mundo. Una vez nombrado, el mundo reaparece a quienes lo nombran como un problema que requiere una nueva designación. Los seres humanos no se construyen en el silencio, sino en la palabra (word) y en el trabajo (Work). Lo formuló con claridad Fernández Buey en un texto de introducción al Manifiesto Comunista que no puedo dejar de citar: "Dar nombre a las cosas es fundamental para ser alguien. En el amor no eres nadie sin oír tu nombre en labios de la persona amada. En las cosas de la política y de la lucha social no eres nadie si aceptas el nombre que dan a la cosa, a su cosa, los que mandan. La lucha por nombrar correctamente y con precisión es el primer acto de la lucha de clases con conciencia. Marx y Engels sabían esto" (Fernández Buey, 1997, p. 20).

\section{Destino e historia}

Las maneras de decir el mundo, las relaciones entre lenguaje y mundo, tienen su reflejo más directo en los modos de pensar la realidad y en las formas de comprometerse con el mundo. La gramática de un discurso tiene efectos performativos en la pragmática, en su valor de uso y de cambio por parte de los hablantes. 0 lo que es lo mismo, la lógica del lenguaje se resuelve, en el terreno cotidiano, en una dinámica socio-lógica, en prácticas sociales y en formas de vida.

Si se olvida esto, se corre el riesgo de quedar cautivos del hechizo del lenguaje, de confundir lenguaje y mundo. Como había señalado antes, el lenguaje acompaña el mundo, lo expresa, pero no es el mundo; podemos convertirlo en acción y en celebración, pero no fundirlo con el mundo; es un ejercicio, no una vida. El nombre de la rosa no es la rosa. Mientras el discurso filosófico de Heidegger se construye como un idiolecto, el discurso pedagógico de Freire se articula como un sociolecto.

El lenguaje también se concreta en el tiempo, forma parte de la historia y por tanto adquiere una dimensión ontológica y epistemológica. Heidegger concibe la historia como destino, su compromiso -su entrega, diríamos más bien- tiene una impronta trágica y agónica. "El suceder de la historia se presenta como destino de la verdad del ser a partir de dicho ser." [CSH, 46-47]. 
En este destino, dice Heidegger apoyándose en Hölderlin, "Occidente no está pensado de modo regional, como lo opuesto a Oriente, no está pensado como Europa, sino desde el punto de vista de la historia universal, desde la proximidad al Origen." [CSH, 51]. La historia para Heidegger se resuelve en un regreso al Origen, en el que "lo sacro", señala, sólo puede llegar a manifestarse si "el ser mismo se ha abierto en su claro y llega a ser experimentado en su verdad." (CSH, 51-52). Historia como epifanía, como relato sagrado que nos re-liga a la verdad, y comprensión del ser como "lo transcendens por antonomasia" [CSH, 49]. El ser humano padece el olvido del ser, y en ese olvido vaga sin rumbo. Padecemos el destierro de la patria, del lugar del origen. Por eso el ser permanece oculto. "Pero el destino del mundo se anuncia en la poesía sin haberse revelado todavía como historia del ser." [CSH, 52].

El destierro del ser humano adquiere en Marx la expresión de extrañamiento, de alienación, según Heidegger. "Ni la fenomenología ni el existencialismo llegan a esa dimensión en la que resultaría posible por primera vez un diálogo productivo con el marxismo" [CSH, 53). Pero, en cualquier caso, el ser humano ha dejado de estar re-ligado para estar re-legado, desterrado de la verdad del ser: "expulsado de la verdad del ser, el hombre no hace más que dar vueltas por todas partes alrededor de sí mismo en cuanto animal rationale." [CSH, 56]. Cuando la razón no alcanza a la comprensión de la verdad, acudimos a la poesía; cuando el conocimiento no es suficiente, nos ayudamos de las metáforas. Y así, por la vía de la metáfora, "el hombre es el pastor del ser", "el hombre es el vecino del ser" porque "mora en la proximidad del ser", en esa "casa del ser" que es el lenguaje.

Lo que para Heidegger se enuncia y se anuncia [la verdad y el regreso a la casa del ser], para Freire es denuncia. Hay verdades que se saben y se sienten: "No se recibe democracia de regalo. Se lucha por la democracia. No se rompen las amarras que nos impiden ser con una paciencia de buenas maneras, sino con el pueblo movilizándose, organizándose, conscientemente crítico. Con las mayorías populares no sólo sintiendo que vienen siendo explotadas desde que se inventó Brasil, sino uniendo también al sentir el saber que están siendo explotadas, el saber que les da la raison d'être del fenómenos, como alcanzan preponderantemente el nivel de su sensibilidad." [CQPE, 131].

Así pues, los compromisos de Heidegger y de Freire con la historia difieren. Para el primero, la historia, como vimos, es destino, es necesidad, es fatalidad o fatuum. Para el pensador alemán la historia es, en términos del escultor vasco Eduardo Chillida, para el que escribió unos hermosos textos [Heidegger, 2009), un "elogio del horizonte". Por el contrario, la historia, para el educador brasileño, es un espacio abierto, un horizonte, pero no arcano ni lejano, sino al alcance de la mano, visible y realizable, aquí y ahora. La historia para Freire es contingencia, es la materia de lo pensable y de lo posible. Ambos han construido su relato "pensando entre las ruinas", por utilizar la expresión que da título a otra obra reciente entre otros dos pensadores, Wittgenstein y Santayana. [Hodges y Lachs, 2011].

\section{Horizontes de sentido}

Siguiendo con la imagen del horizonte, es posible resaltar diferencias de fondo en el horizonte de sentido de los dos pensadores. El horizonte de Heidegger es mito-lógico: el futuro de la humanidad es un pasado anterior al pasado, un tiempo antes del tiempo. "En la filosofía, y en el camino de la metafilosofía, las grandes sistematizaciones culminaron en grandes mitos. El saber absoluto del espíritu absoluto [Hegel], el comunismo integral y el hombre total [Marx], el superhombre que 
acepta el eterno retorno de lo idéntico (Nietzsche), la verdad del ser como tal ser (Heidegger], han sido y son todavía grandes mitologemas modernos y mayores que relevan a otros mitologemas antiguos y un tanto agotados no obstante su persistencia [Axelos, 1980, pp. 23-24].

Por el contrario, el horizonte de Freire es u-tópico: declara que su querencia hacia la lectura y la escritura está orientada hacia cierta utopía, al servicio de una ciudadanía por reinventar. Pero este horizonte utópico requiere otorgar a la palabra utopía su auténtico significado. Frente a un realismo alicorto, el término utopía encierra, en su misma negación [ $u=$ no], su propia inversión, su propia positividad y potencialidad. Utopía significa, planamente, no-lugar. El salto semántico que supone traducir y confundir no-lugar por no-posible o imposible ha derivado en un tremendo descrédito histórico de la razón utópica o de las utopías pensables. Frente al uso y a la creencia común, utopía no es algo imposible o irrealizable o un producto de la fantasía. Antes bien, utopía es un espacio por ocupar, por conquistar, por recrear, en el que la imaginación de los seres humanos, alimentada por esos sueños capaces de vislumbrar la mejora de sí mismo y de los demás, juega un papel en absoluto despreciable. La utopía, pues, es el lugar propio del imaginario social. Imaginación dialéctica [Kant], dialógica [Bajtin], sociológica [C. W. Mills], instituyente [Castoriadis], radical [Peter McLaren], todas desembocan, como corrientes que se encuentran, en las orillas de la utopía, sorteando una y otra vez los diques mentales de contención, horadando incesantemente los muros de la necesidad, redibujando continuamente los contornos de nuestra realidad.

La utopía, pues, no es una región ideal de esencias, no es el reino del más allá ni la tierra prometida. Si se me permite la expresión freireana, utopía es una palabra generadora, que cristaliza en el encuentro dinámico entre teoría y práctica. Dicho de otro modo, pensar una utopía es ya comenzar a realizarla. Explicar una utopía es implicarnos en su consecución. La utopía y la esperanza freireana, señala José Eustáquio Romão, no se confunden con lirismo. Por el contrario, "la utopía para Paulo Freire se objetiva en el horizonte de la humanidad, que es capitaneada por la esperanza activa. Ambas exigen conocimiento crítico de la realidad y compromiso en una acción transformadora" [Romão, 2003, pp. 94-95].

\section{Existencia y esencia: claro y oscuro}

Podemos preguntarnos ahora: ¿qué lugar ocupa el ser humano en este horizonte de sentido? Heidegger responde, desde su paleta de claroscuros, que la propia metafísica supone el olvido del ser. "En todos los casos estamos pasando por encima de la esencia, basándonos precisamente en el fundamento del propio proyecto metafísico". Se trata, podría decirse, de una reedición del relato de un pecado original, de un error de partida, en el que se basa la interpretación metafísica del ser humano y su constitución ontológica. "A estar en el claro del ser es a lo que yo llamo la exsistencia del hombre. Sólo el hombre tiene ese modo de ser, sólo de él es propio." [CSH, 27-28].

"La esencia del Dasein [Da-sein: ser-aquí] reside en su ex-sistencia”, continúa diciendo [CSH, 29]. Esto es, "el hombre se presenta de tal modo que es el 'aquí', es decir, el claro del ser." (p. 30). "Lenguaje es advenimiento del ser mismo, que aclara y oculta" [CSH, 31].

En cualquier caso, Heidegger introduce una idea interesante, que nos hace pensar: "En cuanto exsistente, el hombre soporta el ser-aquí, en la medida en que toma a su 'cuidado' [sorge] el aquí en cuanto claro del ser. Pero el propio ser-aquí se presenta en cuanto 'arrojado'. Se presenta en el arrojo del ser, en lo destinal que arroja a un destino." (p. 33). Aquí Heidegger parece anticiparse 
a la necesidad de que los seres humanos cuiden los unos de los otros [los nuevos movimientos sociales han puesto en circulación un neologismo para referirse a la "cuidadanía"], si bien veremos que el concepto de tomar a su cuidado acabará traduciéndose en la práctica como quedar subordinado, en nueva vuelta de tuerca hegeliana de la dinámica del amo y del esclavo.

Por otra parte, Heidegger toma distancia de Sartre cuando señala que, en la propuesta de este último, "la primacía de la existentia sobre la essentia sin duda justifica el nombre de 'existencialismo'" [CSH, 36], pero esta tesis no tiene "ni lo más mínimo en común con la frase de Ser y tiempo", pues "de lo que así se trata es de preparar algo pre-cursor" [CSH, 36]. Sartre todavía se mueve en la estela de la tardo-metafísica, pero Heidegger está anunciando el advenimiento del pensamiento post-metafísico [que no es ulterior en la línea del tiempo, que no viene después, sino que es la condición para que sea posible la experiencia originaria, fundacional, del pensar], un pensamiento que no se reduce a razonar, que no se concibe logo-céntrico, sino que consiste en la actividad misma del pensar, en aquella relación que nos conduce de camino al habla, una experiencia en la que se supera la dicotomía entre sujeto y objeto. El existencialismo de Sartre es un nombre que no se corresponde con el proyecto o proyección que Heidegger realiza sobre el "humanismo", se queda corto [CSH, 44], porque el ser "se da" pero "sigue impensado todavía" [CSH, 46].

\section{Humano, demasiado humano}

Con su toma de distancia respecto de Sartre, Heidegger quiere marcar una ruptura con la tradición: el lenguaje de la tradición [sus categorías, sus conceptos, sus nombres] nos impide vislumbrar el claro en el bosque, nos impide traer a presencia la dignidad del ser humano: "el único pensamiento es el de que las supremas determinaciones humanísticas de la esencia del hombre no llegan a experimentar la auténtica dignidad del hombre. En este sentido, el pensamiento de Ser y tiempo está contra el humanismo. Pero esta oposición no significa que semejante pensar choque contra lo humano y favorezca a lo inhumano, que defienda la inhumanidad y rebaje la dignidad del hombre. Sencillamente, piensa contra el humanismo porque éste no pone la humanitas del hombre a suficiente altura." [CSH, 37-38). Pero el precio de romper con la tradición es encontrarse "arrojado", "arrojado por el ser mismo a la verdad del ser, a fin que, exsistiendo de ese modo, preserve la verdad del ser para que lo ente aparezca en la luz del ser." Ahora bien, "si acaso y cómo aparece, si acaso y de qué modo el dios y los dioses, la historia y la naturaleza entran o no en el claro del ser, se presentan y se ausentan, eso es algo que no lo decide el hombre. El advenimiento de lo ente reside en el destino del ser." Queda abierta la pregunta de si el ser humano encontrará "lo destinal y adecuado a su esencia." [CHS, 38). En definitiva, el quehacer del ser humano en tanto que ex-sistente es "guardar la verdad del ser. El hombre es el pastor del ser" [CSH, 38-39]. Tal es el significado que otorga a la palabra "cuidado": el hombre, en definitiva, es el pastor de sus pensamientos. Es así como la filosofía puede llegar a convertirse en una meditación y en una oración. La ex-sistencia acaba reducida a una experiencia de ex-stasis, extática. Queriendo escapar de la tradición logocéntrica, Heidegger acaba refugiado en una tradición mística. El camino al habla se convierte en el camino al silencio. Pero la vía del silencio es una vía solipsista, es una vía ensimismada. "El ser 'es' él mismo", sostiene Heidegger. "Esto es lo que tiene que aprender a pensar y experimentar el pensar futuro" [CSH, 39]. Más adelante, alude a las acusaciones sobre Ser y tiempo por abocar a un callejón sin salida, y él mismo se adelanta a las críticas acerca de las chácharas sobre "la verdad del ser" y la "historia del ser". Lo que importa es que la verdad llegue al lenguaje, y tal vez el lenguaje reclame "el justo silencio en lugar de una expresión precipitada" [CSH, 58]. 
Cabe una lectura política de esta línea de pensar profética. Acaso Heidegger pudo llegar a pensar que fue el destino del ser el que le reveló la misión de educar a las generaciones venideras abrazando la causa nacionalsocialista, convirtiéndose en una "encarnación" de la verdad del ser. Acaso la claridad del ser le convirtió en un "iluminado", transfigurado por la luz, no en su forma de lucidez de la razón sino de revelación de la verdad. Tras su "fracasada excusión a la política, Heidegger ha aprendido que 'la preparación de lo verdadero' no se produce inmediatamente." Pero Heidegger se convierte en paciente guardián del ser, de lo que está por-venir, del ad-venimiento. No hay una sola palabra suya de retractación, de reconocimiento de su error: a su juicio, no se ha equivocado, sino que su anuncio ha llegado demasiado pronto. "El nacionalsocialismo realmente existente se convierte para él cada vez más en un sistema de la revolución traicionada, que su manera de ver representaba una revolución metafísica, 'un hacerse manifiesto del ser' [Seyn] en el suelo de la comunidad de un pueblo. De esta manera, el auténtico nacionalsocialista, y como tal continúa sintiéndose también Heidegger, tiene que pasar a ser un pensador en tiempos de indigencia." Y es así como Heidegger "se inscribe a sí mismo en su historia del ser como un heraldo que ha llegado demasiado pronto y por eso corre el peligro de ser triturado y rechazado por su época. Se siente hermano de Hölderlin." [Safranski, 2003, p. 340).

\section{Sueños y pesadillas}

Solemos advertirnos que hemos de tener cuidado con aquello que deseamos porque a veces nuestros deseos se cumplen. Lo mismo sucede con los sueños. Soñar, soñar despiertos, o lo que es lo mismo, proyectar nuestros deseos, es una actividad constitutiva de los seres humanos. Metáfora e imperativo, la relación entre sueño y realidad ha sido uno de los hilos dorados que ha recorrido la historia del pensamiento de la humanidad, la gran cadena del ser, en Occidente y en Oriente. Desde la parábola de Chuang Tzu que dudaba de si había soñado ser una mariposa o era la mariposa la que soñaba ser Chuang Tzu, pasando por la sentencia de Shakespeare de que "estamos hechos de la misma materia de los sueños" hasta el emblemático I have a dream, los sueños forman parte de nuestra dimensión creativa. En el discurso del rectorado pronunciado en 1933, Heidegger había anunciado, con el ascenso del nacionalsocialismo, un segundo comienzo en la historia de la humanidad. En este discurso abanderaba una lucha contra la universidad de los profesores funcionarios. Heidegger confesaría años después, en 1950, en una carta a Jaspers que "soñaba" y que "en fondo pensaba solamente en la universidad, que era lo que tenía en la cabeza." [cit. Safranski, 2003, pp. 303-304). En ese trasfondo, el 25 de noviembre de 1933 Heidegger pronunció en la fiesta de la matriculación "un discurso programático sobre El estudiante alemán como trabajador. Con formulaciones en las que resuenan pensamientos del ensayo El trabajador, de Ernst Jünger, aparecido en 1932, Heidegger polemiza contra la arrogancia de los intelectuales. [...] El estudiante ha de entender, muy humildemente, el estudio como "trabajo" [...] y puesto que "el estado nacionalsocialista es el Estado de los trabajadores", dice Heidegger, los estudiantes cada uno en su puesto, habrían de sentirse "en servicio" con su investigación y saber." [Safranski, 2003, p. 305). Heidegger, que, en el desarrollo de su filosofía, quiso mantener libre el espíritu frente a la orientación a la praxis, defiende con esta proclama un uso doctrinario de la ciencia en aras de los fines nacionales.

Vayamos ahora a Freire. En su sexta carta pone el ejemplo concreto de un grupo de estudiantes que, ante el comportamiento indebido de una maestra, "querían relaciones democráticas basadas en el respeto mutuo. Se negaban a la obediencias ciega, sin límites, del autoritarismo." [CQPE, 92). Freire conjeturaba que posiblemente algunos de aquellos adolescentes salieron a las calles, en una protesta popular contra la corrupción, y "diciendo a gritos que vale la pena soñar." Es la 
experiencia de "cuatro horas con noventa adolescentes que me reforzaron la alegría de vivir y el derecho a soñar." [CQPE, 93]. Pero antes, en la quinta carta había registrado un episodio no menos elocuente: "¿Acostumbras a soñar?, preguntó cierta vez un periodista de televisión a un niño de diez años, trabajador rural, en el interior de Sao Paulo. No, le dijo el niño sorprendido por la pregunta, yo sólo tengo pesadillas." [CQPE, 77]. Freire distingue así la delicada frontera entre los sueños y las pesadillas. A veces los sueños de la razón producen monstruos, reza uno de los célebres cuadros de Goya. A veces los sueños, convertidos en delirios, pueden tendernos trampas.

\section{Tramas y trampas}

En su diario de pensamientos, Hannah Arendt, que conocía bien a Heidegger y por el que había sentido algo más que admiración, le dedica en 1950 una fábula tan breve como magnífica titulada "Heidegger, el zorro", que resulta definitiva. En esta escena Arendt ofrece nueva luz -texto sobre texto, cuadro sobre cuadro-, acerca del pensamiento de Heidegger: "Érase una vez un zorro con tan poca astucia que no solo caía continuamente en las trampas, sino que era incapaz de distinguir entre lo que era una trampa y lo que no lo era. [...] En su asombrosa ignorancia [...] se le ocurrió una idea totalmente nueva e insólita entre los zorros: construyó su madriguera en una trampa. [...] A nuestro zorro se le ocurrió decorar su trampa con gran belleza, y pertrecharla con carteles inequívocos por todas partes en los que se decía claramente: 'Venid todos aquí, esto es una trampa, la trampa más hermosa del mundo.' [...] Si querías visitarlo cuando estaba en casa, tenías que entrar en su trampa. Desde luego todos, excepto nuestro zorro, podían salir de ella. Estaba hecha, literalmente, a su medida. Pero el zorro que vivía en la trampa decía con orgullo: 'Me visitan tantos en mi trampa que me he convertido en el mejor de todos los zorros.' $Y$ algo de verdad hay en ello: nadie conoce mejor la naturaleza de las trampas que aquel que se encuentra toda su vida dentro de una de ellas." (Arendt, 2013, pp. 125-126].

Hasta aquí esta fábula moral sobre Heidegger, en la que sin duda, Arendt toma distancia de su mentor. Pero si aquí hay ironía, en un texto de la filósofa titulado "la crisis de la educación" encontramos una empatía y una cercanía muy sugerente con el pensamiento de Freire. De una manera muy bella, concluye su artículo afirmando que "la educación es el punto en el que decidimos si amamos el mundo lo bastante como para asumir una responsabilidad por él y así salvarlo de la ruina que, de no ser por la renovación, de no ser por la llegada de los nuevos y los jóvenes, sería inevitable. También mediante la educación decidimos si amamos a nuestros hijos lo bastante como para no arrojarlos de nuestro mundo y librarlos a sus propios recursos, ni quitarles de las manos la oportunidad de emprender algo nuevo, algo que nosotros no imaginamos, lo bastante como para prepararlos con tiempo para la tarea de renovar un mundo común." [Arendt, 1996, p. 208].

Expresando algo similar, Freire, en las "últimas palabras" de las cartas, se refiere a la renovación del mundo, como crecimiento: "un fenómeno vital cuya experiencia inserta a sus sujetos en un movimiento dinámico. La inmovilidad en el crecimiento es enfermedad y muerte." [CQPE, 139]. Para Freire, "crecer es parte de la experiencia vital. Pero justamente porque mujeres y hombres a lo largo de nuestra larga historia, acabamos por ser capaces de, aprovechando los materiales que la vida nos ha ofrecido, crear con ellos la existencia humana -el lenguaje, el mundo simbólico de la cultura, la historia- crecer, en nosotros o entre nosotros, adquiere un significado que trasciende el crecer en la pura vida." La diferencia viene marcada porque nosotros podemos intervenir en el proceso de crecer, el crecimiento no es un automatismo de la especie. Porque 
"nosotros somos seres indiscutiblemente programados pero de ningún modo determinados. Y somos programados principalmente para aprender, como señala François Jacob [1991]". [CQPE, 39]. Por eso, concluye Freire, "que el saber tiene todo que ver con el crecer es un hecho. Pero es necesario, absolutamente necesario, que el saber de las minorías dominantes no prohíba, no asfixie, no castre el crecer de las inmensas mayorías dominadas." [CQPE, 141].

El saber de Heidegger es un saber consistente, internamente coherente, si bien basado en la astucia de la razón, que recurre a "obvios trucos y sofisterías verbales" (Arendt, 2013: 84). Es un saber que contiene trampas que no siempre es fácil advertir, ocultas o veladas por un discurso enigmático y cautivador. Por el contrario, el saber de Freire es un saber que, pretendiendo superar los límites del sentido común, reconoce la importancia del aprendizaje permanente. Es un saber que, desde su radical apertura al aprendizaje, se despliega y se concreta en múltiples tramas, en tantos relatos como sujetos que pronuncian el mundo con sus propias historias de vida, y tejiendo palabras, lo in-visten y le dan su mejor sentido. El saber de Freire no pretende ser el de la astucia, sino el de la inteligencia sentiente, el de la inteligencia que se mueve y se con-mueve con los otros, el de una razón apasionada, bien temperada. El proyecto educativo de Freire ha sido posible gracias a su com-pasión, esto es, a su pasión compartida por los demás. El proyecto filosófico de Heidegger fue el resultado de un esfuerzo tenaz y crepuscular por romper los límites del lenguaje, por desvelar y revelar lo todavía no-dicho. Se podría decir que Freire vivió el presente con sus coetáneos con una proyección en las generaciones venideras, con un sentido de natalidad, siguiendo la expresión de Arendt. Heidegger, en cambio, vivió de un modo extemporáneo, en una huida hacia el futuro, sub specie aeternitatis, y cuando quiso atrapar su hora presente, cayó en su propia trampa. Heidegger vivió (en) la escritura como elección, como destino elegido. Freire escribió la vida, las palabras de la vida, como programa, como lección. Heidegger hizo de su particular cosmovisión su misión, su destino; Freire convirtió su proyecto educativo, su proyecto de humanización, en un programa de acción, que continúa. A Heidegger podemos llegar a admirarlo como se admira un monumento, con solemnidad, con gravedad; a Freire lo admiramos al tiempo que lo reiventamos, como nos pidió, como se recrea un movimiento, una tradición, una fiesta..., con las pasiones alegres [Spinoza] con las que acudimos a una manifestación cívica.

\section{Melancolía y rebeldía}

El lenguaje de Heidegger nos devuelve a cierta melancolía, el lenguaje de Freire nos invita a una clara rebeldía. La obra de Heidegger perdurará, tal vez, como la de aquellos grandes pensadores solitarios que cargaron, como auténticos titanes, con todo un mundo sobre sus espaldas: un mundo construido con su propia semántica, con la vida secreta de las palabras. La obra de Freire perdurará como la de aquellos otros solidarios que quieren hacer del mundo una comunidad de iguales, que quiere habitar lugares comunes: un mundo en que el lenguaje se expresa en formas de vida social. El reino de Heidegger no es de este mundo ni de este tiempo, el reino [sin trono ni reinado] de Freire es de nuestro mundo y de nuestro tiempo. Heidegger dedicó su vida a enfrentar dos de los tres problemas de la filosofía que enunció Kant en su Crítica de la Razón Pura: ¿Qué puedo conocer? ¿Qué debo esperar? Freire, sin descuidar estas cuestiones, privilegió la tercera, la que otorga la dimensión moral y política a los seres humanos: ¿Qué debo hacer? Este sesgo por el "hacer" tiene que ver con las asociaciones que acompañan a su pensamiento: a Freire se le suele caracterizar no tanto como un teórico [que ejerce la práctica del pensamiento], sino como activista teórico (que ejerce el pensamiento de la práctica). Y esto, a su vez, tiene un precio. Precisamente la claridad expositiva de Freire, su voluntad didáctica, le ha hecho sospechoso para 
las ciencias sociales de falta de densidad o profundidad. Una acusación que viene reforzada por su apelación a la "estructura de los sentimientos", esto es, a la concepción de la revolución como un acto de amor.

En cualquier caso, no es casual que la invocación y la incitación kantiana a ejercer la razón práctica, de manera autónoma [recordemos Pedagogía de la autonomía], a través de su conocido Sapere Aude! se acompañe con la recomendación de acudir a la paideia. "El ser humano solamente puede ser humano a través de la educación. Él es lo que la educación hace de él", señala Kant. Tal motivo es el mismo que recrea Gadamer a punto de cumplir los cien años, compendiando su trayectoria, en la magnífica lección pronunciada ante un grupo de estudiantes y que lleva por título "La educación es educarse" [Gadamer, 2000).

Como ya había apuntado antes: "La exclamación kantiana, ¡Atrévete a pensar!, lejos de estar caduca, se convierte en todo un grito de insurgencia en esta época de incertidumbres, en esta sociedad de riesgo." De modo que no se puede estar de acuerdo "con las críticas postmodernas que acusan a Kant y a sus epígonos de fundacionalistas, señalando que su teoría se basa en certezas cartesianas. Por el contrario, el proyecto de Kant, calificado como de auténtico giro copernicano en el terreno de la epistemología, pone cerco al conocimiento humano toda vez que señala sus condiciones de posibilidad. Cuando Kant dinamita "la cosa en sí" a favor de "la cosa en ti", o lo que es lo mismo, concluye que el acceso al conocimiento de la realidad únicamente es posible con perspectiva humana, con el filtro de nuestra propia mirada, está disminuyendo el perímetro de nuestras certezas y aumentando, en correspondencia, el ámbito de nuestra autonomía, de nuestra libertad, de nuestra contingencia, y por tanto, de nuestra responsabilidad." [Beltrán, 2003, p. 20] .

\section{Caminar, pensar, hacer}

En este sentido, podría decirse que Freire actualiza de manera ejemplar la tradición de los peripatéticos, aquellos que enseñaban conversando mientras caminaban con sus congéneres. La manera contemporánea de caminar para un pensador cosmopolita como Freire es la del viaje. Toda la obra de Freire, frente a la de Heidegger, se puede entender en clave de una filosofía del viaje, en el que las geografías físicas [las personas y lugares que conoció) encuentran su correspondencia en sus geografías mentales, ese incesante y fértil work in progress que se iba desplegando en numerosas obras, en las que gustaba registrar cómo cada una de ellas se habían redactado en diferentes circunstancias, como respuesta a experiencias educativas, reconociendo préstamos de lecturas muy variadas y de encuentros que tenían lugar con intelectuales, con maestras y maestros, pero también y sobre todo con mujeres y hombres deprivados de educación, con personas analfabetas. Así pues, la obra de Freire se caracteriza por su dinamismo, por su expansión o si se prefiere, en sus propios términos, por su "comunicación" [Freire, 1973]. En cambio, la obra de Heidegger se caracteriza por su estatismo rayano en lo contemplativo, y en ocasiones en lo ex-stático (como deja ver en su reconocimiento a "Meister Eckhart, el viejo maestro de lecturas y de la vida" (Heidegger, 2003, p. 31). Heidegger no viajó mucho, apenas llevó a cabo algunas "estancias", como la que recogió en el libro de título homónimo sobre su primera visita a su querida Grecia, (Heidegger, 2008); en tanto que guardián del ser, prefirió la contemplación a la acción, y acabó asumiendo una suerte de exilio interior.

En esa dimensión moral y política que he señalado antes - desde la pregunta de Kant, ¿qué puedo hacer? - puede situarse el legado educativo de ambos pensadores. Heidegger tal vez fue 
un magnífico profesor de filosofía, un pensador de fondo, pero cuyas pretensiones filosóficas que el ser humano estuviera a la altura de la verdad- le hacían caminar mirando tan alto que acabó tropezando, en la arena política, por no mirar a su propio suelo, a su propia vecindad. Freire fue un magnífico pedagogo, un arquitecto de las palabras que tendió puentes entre textos y contextos, entre palabras y mundo; gozaba del aire libre, del que se dice que también es una forma de arquitectura, y es así, desde la práctica de la libertad, como pudo construir casas del saber [antes que cabañas para pensar] y círculos de cultura. Heidegger transitó ensimismado, sirviéndose de conceptos y de metáforas, por sendas perdidas, en el esfuerzo de en-caminarse al habla, al lenguaje, a la casa del ser. Le gustaba caminar en solitario, un caminar próximo a su residencia, y le gustaba aislarse en su "cabaña", desde ahí se desplazó a mundos lejanos, seminales y ancestrales, a los que evocaba y convocaba. Freire transitó, sirviéndose también de palabras, por las calles de la historia, en su esfuerzo por participar y ser parte de la historia cotidiana, la que trazan de manera anónima con letra cursiva y con minúsculas la gente común. A Freire le gustaba estar en compañía, y su soledad -cuando la practicaba- era de una naturaleza sociable. Prefirió el cultivo de la solidaridad y de la amistad a la gestión de la soledad. Heidegger elaboró su particular credo filosófico desde su concepción de la naturaleza profética de la educación. En Heidegger la lección, con frecuencia, era derivaba de una meditación, y ocasionalmente, de una oración [en forma de poema o de pensamiento poético]. En Freire la lección, escrita o pronunciada, era el resultado de una extensa y continua conversación. El discurso de Heidegger, cuya riqueza, densidad y tensión filológica y gramatical era innegable, tenía mucho de poético y de metafórico, con figuras expresivas evocadoras, sugerentes y enigmáticas. En cambio, el discurso de Freire fue ganando con el tiempo claridad expositiva, voluntad pedagógica, sin perder rigor ni riqueza expresiva, pero Freire prefería "la prosa del mundo", parafraseando a su citado MerleauPonty [1971], y era un ejemplo elocuente del aforismo que señala que "la claridad comienza por uno mismo" Apple, 1989].

Freire trazó su credo pedagógico desde su firme convicción en la naturaleza política de la educación. Plano sobre plano, Heidegger privilegió la experiencia y los movimientos del pensar; mientras que Freire dio preeminencia a la reflexión desde la acción, al "todo que hacer". Heidegger pensó, desde las élites, el destino del pueblo [convertido en patria y en nación] sin el pueblo, se erigió en una suerte de elegido del ser para encarnar la verdad. Ejerció de este modo una forma de despotismo metafísico ilustrado, una pedagogía de corte "aristocrático". Freire construyó su obra educativa pensando en el pueblo [convertido en pueblos y ciudades, en personas y lugares concretos] y junto con el pueblo: el nombre de pedagogía "popular" para su obra le hace plena justicia.

Ambos alumbraron nuestros años de aprendizaje y hoy siguen inspirando ese periplo que constituye nuestra incesante formación. Su pensamiento alumbra nuestro devenir por un mundo que nos explica y al que tratamos de dar explicación. Heidegger nos exige un esfuerzo epistemológico desmedido por romper los límites del lenguaje. Por el contrario, Freire, añadiendo pasión a la necesidad - la "pasión de conocer", en sus propios términos [CQPE, 10]-, enriquece la explicación con implicación, la comprensión con el compromiso. Ambos hicieron suya esa tarea de atribuir sentido, en la que a la par somos envío y extravío, legándonos su propia versión -su propio relato- de la aventura de elucidar y dilucidar, de procurar ser lúcidos. Pero si el sueño de Heidegger rozó el delirio, el sueño de Freire convirtió la educación en una práctica para la libertad. 


\section{Una celebración y una propuesta}

Una celebración?: He sido lector de Paulo Freire desde mi juventud. Comencé a leer sus libros cuando era un joven estudiante de Magisterio a final de los años 70. Sus obras me siguieron inspirando cuando, al finalizar mis estudios, trabajé como educador de personas adultas durante la década de los 80 y los 90. En 1995 Freire visitó Valencia e impartió un seminario en la Universidad Internacional Menéndez Pelayo, al que asistí con mucho interés. Allí, el maestro Freire impartió unas lecciones inolvidables [que queremos recuperar], con una sencillez que sólo alcanzan quienes tienen el privilegio de transformar el conocimiento en sabiduría después de una vida plena. En la década de los 90 me incorporé a la Universidad para impartir docencia en Magisterio. Desde el primer año, entre las lecturas imprescindibles en mi programa de Sociología de la Educación, incluyo alguna de las obras de Paulo Freire. Ningún estudiante de Magisterio puede acabar sus estudios sin haber leído algún texto de Freire.

A finales de 2010 tuve la fortuna de poder visitar la hermosa región Nordeste de Brasil, invitado por la Profesora Dra. Betania Ramalho, Secretaria de Educación do Rio Grande do Norte, y por la Profesora Dra. Emília Maria da Trindade Prestes, de la UFPB. Me siento afortunado de poder contar con muy buenas amigas y amigos en Natal, en Joao Pessoa y en muchos otros lugares de Brasil. Son tantos que no podría aquí nombrarlos a todos. En Natal ["morando na quela beleza, a cura de toda tristeza", dice el poeta popular Beto Brito] y en las ciudades cercanas puede comprobar que Freire sigue vivo: en las escuelas, en la Universidad, en la Secretaría de Educación; pero también, lo que es más asombroso: está vivo en las calles, a través de esa expresión magnífica de cultura popular que es la literatura de cordel, y de la que el propio Freire era lector, como testimonió en su quinta carta de Cartas a quien pretende enseñar [Freire, 1994, p. 79].

Esa presencia cotidiana de Freire, local y universal al mismo tiempo, hace que su pensamiento y su método de la palabra generadora -que es una invitación constante a la acción- pueda ser considerado un patrimonio de la humanidad. Freire sonreiría contento de saber que una experiencia tan humilde pero tan poderosa como la de Angicos se está celebrando 50 años después. [Mientras escribo estas palabras releo el libro de Carlos Lyra, en la edición de 1996, que me regaló la Doctora Aliete Borman). "As cuarenta horas de Angicos" son cuarenta razones para la esperanza. Una esperanza que no es una espera sino un trabajo y una exigencia. Paulo Freire inició su obra hablando de la pedagogía del oprimido. Ahora hemos de continuar su obra - como el quería, reinventándola- con una pedagogía del reconocimiento, recreando el sentido de su trabajo y tendiendo puentes entre sus palabras y nuestro mundo del siglo XXI, entre sus textos y nuestro contexto.

Para mí es un honor compartir estos cincuenta años de una experiencia pionera en educación, en la que Freire puso en práctica su método de la palabra generadora. La invitación que ahora me hacen los amigos del Nordeste -y que en esta ocasión me llega a través de Adriana Diniz- a participar en este magnífico evento, forma parte, sin duda, de "la trama poética de la vida". Esa trama prodigiosa en la que el azar se ordena a nuestro favor para romper fronteras, haciéndonos

3 Los párrafos que tienen lugar a continuación son una adaptación de mi contribución, como saludo internacional, a la celebración de Las 40 horas de Angicos, que tuvo lugar en abril de 2013 en Angicos [Río Grande do Norte]. La propuesta que viene a continuación se añade a este reconocimiento. 
cercanos y hermanos, más allá de toda contingencia, en la búsqueda común de la mejora de uno mismo, de los demás y de la humanidad. Hoy no puedo dejar de recordar aquellas palabras en las que Freire se preguntaba: “¿qué sería del mundo sin educación?”

Belota, sapato, voto, povo, salina, feira, goleiro, milho, cozinha, ti[j]ela, chibanca, xique-xique, expresso, bilro, amofada. Pequeñas palabras que fundan un mundo, palabras que nos alumbran y nos entregan a la vida, palabras que nos hacen nacer a la utopía, sabiendo que "a utopia/ é a própia luta/ de cada dia", y que nos invitan a que "plantemos una tenda en cada estrela".

Una propuesta: Sigamos plantando una tienda en cada estrella: El método de la palabra generadora se debe a Paulo Freire, pero ya no es de Freire: ahora pertenece al mundo. Son muchos, cada vez más, los educadores y educadoras de buena parte de nuestro mundo que, tomado conciencia del valor de la palabra como vía de acceso al saber universal y a la emancipación, han empleado y siguen empleando para sus clases de alfabetización el método de la palabra generadora. Las tasas de analfabetismo están disminuyendo pero todavía siguen siendo elevadas en algunas regiones de nuestro mundo. Además, en nuestra sociedad de conocimiento, el analfabetismo adopta nuevas expresiones. Mientras siga habiendo desigualdades sociales, seguirá persistiendo el analfabetismo (en sus formas instrumentales, funcionales, digitales...). Y mientras continúe el analfabetismo, el método de la palabra generadora -con adaptaciones, transformaciones, actualizaciones- seguirá siendo un patrimonio intangible, inmaterial, de la humanidad.

La humanidad sigue peregrinando entre sendas perdidas, buscando claridad en su devenir. Parémonos por un instante "a la sombra de este árbol". La propuesta, inspirada en el cincuentenario de "las 40 horas de Angicos" es tan sencilla como u-tópica [porque todavía es un no-lugar, es inédita]: No sería impensable (y si es pensable, es posible] elevar una petición para que el método de la palabra generadora sea reconocido y alcance el estatuto de patrimonio inmaterial de la humanidad. Convirtamos este deseo en un "inédito viable". ${ }^{4}$ Otorguemos a las palabras educación, libertad, autonomía, utopía sus auténticos significados, y participemos en la vida de las palabras. "Vale la pena soñar" [CQPE, 93]. Plantemos una tienda en esta estrella.

\section{Bibliografía}

Apple, Michael W. [1989]. Maestros y textos, Una economía política de clase y sexo en educación. Barcelona: Paidós.

Arendt, Hannah [1996]. Entre el pasado y el presente. Ocho ejercicios de reflexión sobre la política. Barcelona: Península.

Arendt, Hannah [2013]. Existencialismo y compromiso. Barcelona: RBA.

Axelos, Kostas [1980]. Horizontes del mundo. México: FCE.

Beltrán, José [2003]. La il.lusió socràtica o les ribes de la utopia. En Raymond A. Morrow y Carlos Alberto Torres, Llegint Freire y Habermas [pp. 11-21]. Xàtiva: Ediciones del CREC.

4 Desde 2017, cuatro años después de escribir este texto, el archivo Paulo Freire integra el Programa Memoria del Mundo de la UNESCO. En buena medida, lo que antes fue una posibilidad ahora es una realidad: lo inédito se ha hecho viable. 
Beltrán, José [2006] Prólogo. Espacios de liberación. Contra la retórica de la globalización- En Carlos Alberto Torres, Educación y Neoliberalismo. Ensayos de oposición [pp. 7-23). Madrid: Editorial Popular.

Berger, John [2000]. Modos de ver. Barcelona: Gustavo Gil.

Fernández Buey, Francisco [1997]. "Para leer el Manifiesto Comunista”. En Karl Marx y Friedrich Engels, El Manifiesto Comunista. Barcelona: El viejo topo.

Freire, Paulo [1972]. ¿Extensión o comunicación? La concientización en el medio rural. Madrid: Siglo XXI.

Freire, Paulo [1994]. Cartas a quien pretende enseñar. Madrid: Siglo XXI.

Freire, Paulo, Gadotti, Moacir y Guimarães, Sergio [2001]. Pedagogia. Xàtiva: Edicions del CREC.

Freire, Paulo y Illich, Ivan [2004]. Diàleg. Xàtiva: Edicions del CREC/IPF.

Gadamer, Hans-Georg [2000]. La educación es educarse. Barcelona: Paidós.

Heidegger, Martin [1996]. Carta sobre el humanismo. Madrid: Alianza.

Heidegger, Martin [2003]. Camino de campo. Valencia: Pre-textos.

Heidegger, Martin [2008]. Estancias. Valencia: Pre-textos.

Heidegger, Martin [2009]. El arte y el espacio. Barcelona: Herder.

Hodges, Michael y Lachs, John [2011]. Pensando entre ruinas. Wittgenstein y Santayana sobre la contingencia. Madrid: Tecnos

Jaspers, Karl [1990]. Notas sobre Heidegger. Madrid: Mondadori.

Keenedy, William B. [2004). Peregrins d’allò evident: o no tan evident?. En Paulo Freire e Iván Illich, Diàleg [pp. 31-41]. Xàtiva: Edicions del CREC/IPF.

Merleau-Ponty, Maurice [1971]. La prosa del mundo. Madrid: Taurus.

Morrow, Raymond A. y Torres, Carlos Alberto [2003]. Llegint Freire y Habermas. Xàtiva: Ediciones del CREC.

Romão, José Eustáquio [2003]. Pedagogia dialògica. Xàtiva: Edicions del CREC/IPF.

Rorty, Richard [1989]. La filosofía y el espejo de la naturaleza. Madrid: Cátedra.

Torres, Carlos Alberto [1980). Las corrientes filosóficas que secundan la filosofía de Paulo Freire. Colección Pedagógica Universitaria, 9, 7-26.

Torres, Carlos Alberto [2006]. Educación y Neoliberalismo. Ensayos de oposición. Madrid: Editorial Popular.

Safranski, Rüdiger [2003]. Un Maestro de Alemania. Martin Heidegger y su tiempo. Barcelona: Tusquets. 